\title{
APPLICATION OF EVAPORATIVE COOLING FOR THE CONDENSATION OF WATER VAPORS FROM A FLUE GAS WASTE HEAT BOILERS CCP
}

\author{
Nikolay Galashov ${ }^{1, *}$, Svyatoslav Tsibulskiy ${ }^{1}$, and Alexander Kiselev ${ }^{1}$ \\ ${ }^{1}$ National Research Tomsk Polytechnic University, 634050 Tomsk, Russia
}

\begin{abstract}
The object of the study are boilers that burn organic fuel and the recovery boilers (RB) of the combined cycle plant (CCP), which are also working on the products of the combustion of hydrocarbon fuels. The purpose of research is to find technologies that increase efficiency of the thermal power plant (TPP) and technologies that reduce the environmental impact on the environment by burning fossil fuels. The paper deals with the technology of the boilers burning hydrocarbon fuel with condensation of water vapor from the exhaust flue gases. Considered the problems caused by using of this technology. Research shows that the main problem of this technology in the boilers is the lack of reliable methods of calculation of heat exchangers, condensers. Particular attention is paid to the application of this technology in the recovery boilers combined-cycle plants, which are currently gaining increasing use in the generation of electricity from the combustion of gas in power plants. It is shown that the application of technology of condensation of water vapor in RB CCP, the temperature decreases of exhaust gases from 100 to $40{ }^{\circ} \mathrm{C}$, allows increasing the efficiency of the RB with $86.2 \%$ to $99.5 \%$, i.e. at $12.3 \%$, and increase the efficiency of the CCP at $2.8 \%$.
\end{abstract}

\section{Introduction}

For many years, the design and operation of boilers that burn organic fuel, one of the main tasks was to prevent condensation of the vapor in the exhaust flue gases, as contained in the condensate, sulfur oxides, nitrogen and other harmful substances lead to metal corrosion of the heating surfaces and flues, and as the destruction of the inner wall of the chimney.

In order to prevent condensation of the vapor is necessary to maintain the temperature of the flue gases above the dew point, at which the combustion of natural gas, depending on the excess air, is about $40-60{ }^{\circ} \mathrm{C}$, and the combustion of coal, depending on the chemical composition of the flue gas may be below or above this temperature. Taking into account the reducing the temperature exhaust gases at lower boiler loads for nominal mode it usually take for $70-110{ }^{\circ} \mathrm{C}$ gas and coal $140-160{ }^{\circ} \mathrm{C}$. High temperature leads to a great loss of

\footnotetext{
Corresponding author : gal@,tpu.ru
} 
heat from the exhaust gases, resulting in a gross efficiency of the boiler at the gas does not exceed $95 \%$, and coal $-90 \%$, based on the bottom heat of combustion of fuel. At the same time useless lost heat spent on evaporation of moisture, and oxides are all harmful substances out with the flue gases and pollute the environment.

To improve the efficiency of the boiler, the reliability of the gas ducts, exhaust and chimney, as well as reducing the emission of harmful substances, based on available technology cooling flue gases below the dew point by means of heat exchangers, condensers. This technology is currently recognized as one of the most resource- and energy-efficient and have been widely used in many countries around the world, as evidenced by the rapidly growing number of scientific publications [1-15] and commercial offers for the sale of boilers based on it. While this technology is increasingly used in small boilers running on gas, but there are a number of works on the application of it to the hot water and vapor boilers of high power, as well as in the recovery boilers (RB) combined cycle gas turbines (CCGT) [16].

To provide reliable condensing flue gas temperature should be below the dew point, i.e., when working with natural gas - to be below $44{ }^{\circ} \mathrm{C}$ (excess air ratio 2.5), wherein when calculating the boiler efficiency at higher heating value will be around $99 \%$, while in noncondensing boiler it will be $85 \%$, which reduces fuel consumption by $15 \%$.

The amount of harmful emissions $\left(\mathrm{CO}_{2}, \mathrm{NO}_{\mathrm{X}}\right)$ in the flue gas leaving boiler with condensation of water vapor in 5-7 times lower than in traditional gas-fired boilers. A coalfired boilers have the effect of trapping of harmful substances in the condensation of water vapor from the flue gases even higher.

\section{Application problem}

The combustion of a hydrocarbon fuel, depending on the type of fuel in the flue gas is formed about 10-15\% moisture. To capture moisture from the flue gases and the contact surface applied-exchangers capacitors. Application for cooling flue gas condensing heat exchanger surface display type allows air or water flow in the circuit of stations useful in the process. The coefficients of heat transfer from the flue gas to the heating surfaces with a deep cooling, accompanied by condensation of water vapor, considerably higher coefficients of convective heat and substantially comparable to the heat exchange coefficients for the contact devices. The disadvantages of surface heat exchangers should include large size, which often does not allow to place them directly in the boiler; high cost of the metal, often stainless steel.

More often for dehumidifying contact apply flue gas heat exchangers in which the flue gas for cooling and condensation of the evaporator, which is applied in the cooling of the gases by reaction with droplets or jets of water film. These devices are much smaller in size and surface do not require expensive materials, standing. They have a high heat transfer rate substantially greater than the heat transfer coefficients of convective heat transfer. Their drawback is that the heated water is absorbed from the flue gas oxygen, carbon dioxide, sulfur oxides and becomes corrosive-aggressive properties, so for further use requires cleaning. For natural gas RB CCP condensate practically is not exposed to contamination.

Currently, there are a number of methods for the calculation of heat exchangers with condensation of water vapor from the gas, but the variety of types and designs devices requires further research to improve the methods of calculation of heat exchangers.

Significant problem when using condensing boilers of water vapor from the flue gas is to ensure reliable operation of the flues and chimney. The low temperature of the flue gas with a residual content of water vapor can lead to condensation in the ducts and chimney, and the destruction of equipment. Therefore, after the heat exchanger drained gases 
preheated stream of hot gases passing by the heat exchanger, which leads to underutilization of the heat of condensation in the boiler. At low flue gas temperatures can be for flues and flue pipes to apply new construction materials not subject to corrosion by the condensation of water vapor.

\section{Prospects for the use of technology at CCP}

Consider how is possible to increase the efficiency of RB and efficiency of CCP using this technology in the recovery boiler.

The efficiency of CCP can be determined by the equation $[17,18]$

$$
\eta_{C C P}=\eta_{G T P}+\left(1-\eta_{G T P}\right) \eta_{R B} \eta_{S T P}
$$

where $\eta_{G T P}-$ efficiency of the gas turbine plant (GTP); $\eta_{R B}-$ efficiency of the RB; $\eta_{S T P}-$ КПД steam turbine plant (STP).

For example, take the CCP that has $\eta_{G T P}=0.36$ and $\eta_{S T P}=0.33$. In RB from GTP gases with excess air ratio flow $\alpha_{E X}=2.7$ with temperature $600{ }^{\circ} \mathrm{C}$, and from $\mathrm{RB}$ exhaust to the chimney at a temperature of $100{ }^{\circ} \mathrm{C}$. Efficiency of RB determined by the equation

$$
\eta_{R B}=\frac{h_{G T P}-h_{E X}^{100}}{h_{G T P}-h_{15}}
$$

where $h_{\mathrm{GTP}}$ - enthalpy of gas at the inlet $\mathrm{RB}$, at the given parameters is equal to $650.4 \mathrm{~kJ} / \mathrm{kg}$; $h_{E X}^{100}$ - enthalpy gas at the outlet $\mathrm{RB}$, at the given parameters is equal to $102.4 \mathrm{~kJ} / \mathrm{kg} ; h_{15}=$ $15.4 \mathrm{~kJ} / \mathrm{kg}$ - enthalpy gas at the temperature $15^{\circ} \mathrm{C}$, this is the temperature the air inlet to the compressor GTP. Substituting into the equation (2) the enthalpy can be obtain $\eta_{R B}=$ 0.862 , and from the equation (1) obtain the $\eta_{C C P}=0.542$.

Now, assume that the output gases from the RB set-pin condenser heat exchanger in which the gases are cooled by water to a temperature $t_{E X}=40{ }^{\circ} \mathrm{C}$, which is below the dew point $t_{D P}=43{ }^{\circ} \mathrm{C}$. The moisture content at the inlet of the heat exchanger-condenser at a temperature of $100{ }^{\circ} \mathrm{C}$ and the excess air coefficient $\alpha=2.7$ is $d_{C}=56 \mathrm{~g} / \mathrm{kg}$ dry gases and the output will be $47 \mathrm{~g} / \mathrm{kg}$. Thus, condensation of water vapor flow rate with respect to entering of the RB gases will be $\Delta d_{C}=9 \mathrm{~g} / \mathrm{kg}$. The heat of condensation can be useful in CCP scheme used to heat water or air, and condensation can be used after removal of dissolved gases, such as additional water. In this case, efficiency of RB is determined by the equation

$$
\eta_{R B}^{\text {cond }}=\frac{\left(h_{G T R}-h_{E X}\right)+\left(1-\Delta d_{C}\right)\left(h_{E X}-h_{E X}^{C}\right)+\Delta d_{C} r+d_{C}\left(h_{C}-h_{A W}\right)}{h_{G T R}-h_{15}},
$$

where $h_{E X}^{C}=41.0 \mathrm{~kJ} / \mathrm{kg}$ - enthalpy at $t_{E X}=40{ }^{\circ} \mathrm{C}$ and $\alpha_{E X}=2.7 ; h_{C}-$ enthalpy of the condensate, at the temperature $40^{\circ} \mathrm{C}$ is equal to $167.6 \mathrm{~kJ} / \mathrm{kg}$, heat of condensation $r=2406$ $\mathrm{kJ} / \mathrm{kg} ; h_{A W}=41.9 \mathrm{~kJ} / \mathrm{kg}$-enthalpy of additional water at $10{ }^{\circ} \mathrm{C}$. As a result equation (3), obtain the $\eta_{R B}^{\text {cond }}=0.995$, according to the equation (1) obtain $\eta_{C C P}=0.570$.

Thus, application of the technology of condensation of water vapor in the RB can improve the efficiency with $86.2 \%$ to $99.5 \%$, i.e. $12.3 \%$, and the efficiency of the CCP to increase by $2.8 \%$. 


\section{Conclusion}

Application of technology of boilers with condensation of water vapor from the flue gas is promising to improve the efficiency of facilities and protecting the environment.

- The main problem of the use of technologies of condensation heat from the flue gas in boilers is the lack of reliable methods of calculation of heat exchangers, condensers. This issue requires further research.

- Application of the technology of condensation of water vapor from the of exhaust gases in the RB CCP for example considered it possible to increase efficiency of RB from $86.2 \%$ to $99.5 \%$, i.e. $12.3 \%$, and the efficiency of the CCP to increase by $2.8 \%$.

\section{Acknowledgments}

The work has been supported by the Russian Federal focused program "Research and development on priority orientation of science and technology in Russia 2014-2020", unique identifier 'Applied Research and Experimental Developments' project RFMEFI58114X0001.

\section{References}

1. M. Osakabe, Heat Transfer - Asian 3, 12 (2001)

2. D.F. Che, Y.H. Liu, C.Y. Gao, Energy Convers. Manage. 45, 16 (2004)

3. D.F. Che, Y.D. Da, Z.N. Zhuang, Heat Mass Transfer 41, 6 (2005)

4. X. Shi, D. Che, B. Agnew, J. Gao, Int. J. Heat Mass Transfer 54, 10 (2011)

5. K. Jeong, M. J. Kessen, H. Bilirgen, E.K. Levy, Int. J. Heat Mass Transfer 53, 8 (2010)

6. K. Hwang, C.H. Song, K. Saito, S. Kawai, Appl. Therm. Eng. 30, 8 (2010)

7. X.H. Ma, X.D. Zhou, Z. Lan, Y.M. Li, Y. Zhang, Int. J. Heat Mass Transfer 51, 10 (2008)

8. E. Levy, H. Bilirgen, C. Samuelson, K. Jeong, M. Kessen, C. Whitcomb, International Technical Conference on Coal Utilization and Fuel Systems (2008)

9. D. Hazell, Modeling and Optimization of Condensing Heat Exchangers for Cooling Boiler Flue Gas (Ph.D. Dissertation, Lehigh University, 2011)

10. K. Jeong, Condensation of Water Vapor and Sulfuric Acid in Boiler Flue Gas (Ph.D. Dissertation, Lehigh University, 2008)

11. M. Lavigne, Numerical Simulations of Condensing Heat Exchangers with Oxyfuel Flue Gas (Thesis, Lehigh University, 2010)

12. E. Levy, H. Bilirgen, M. Kessen, D. Hazell, B. Carney, Am. Soc. Mech. Eng. 1 (2011)

13. D.D. Hazell, Modeling and Optimization of Condensing Heat Exchangers for Cooling Boiler Flue Gas (Ph.D. Dissertation, Lehigh University, 2011)

14. P. Frank, Fundamentals of Heat and Mass Transfer (John Wiley\&Sons, Inc., Hoboken, 2007)

15. M. Lavigne, Numerical Simulations of Condensing Heat Exchangers with Oxyfuel Flue Gas (Thesis, Lehigh University, 2010)

16. I.V. Budakov, V.D.Burov, New in the Russian power industry 11, 11 (2011)

17. A.D. Truhny, Combined cycle gas turbine power plants (Publishing House MEI, 2013)

18. R. Kehlofer, B. Rukes, F. Hannemann, F. Stirnimann, Combined-Cycle Gas \& Steam Turbine Power Plants (PennWell Corporation, 2009) 